\title{
ETNOPEDOLOGIA E TRANSFERÊNCIA DE CONHECIMENTO: DIÁLOGOS ENTRE OS SABERES INDÍGENA E TÉCNICO NA TERRA INDÍGENA MALACACHETA, RORAIMA ${ }^{(1)}$
}

\author{
José Frutuoso do Vale Jr. ${ }^{(2)}$, Carlos Ernesto G.R. Schaefer ${ }^{(3)}$ \\ \& José Augusto Vieira da Costa ${ }^{(4)}$
}

\begin{abstract}
RESUMO
O conhecimento indígena sobre a pedodiversidade é o objeto principal da etnopedologia. Nesse sentido, a tradição agrícola e cultural dos índios Uapixana, do tronco lingüístico Aruaque, em Roraima, constitui relevante acervo imaterial de valor etnocientífico, sendo valorizada pela Universidade Federal de Roraima em seus cursos superiores de Educação Indígena no Estado. Neste trabalho confrontou-se a experiência etnopedológica dos índios Uapixana com o Sistema Brasileiro de Classificação de Solos, durante o levantamento de solos da Terra Indígena (TI) Malacacheta. O sistema de classificação etnopedológica existente na comunidade indígena Uapixana da TI Malacacheta identifica e separa todos os principais compartimentos ambientais de ocorrência na área, permitindo relacionar aspectos de simples percepção e identificação (cor, textura, profundidade, vegetação) com aspectos cognoscíveis (uso, tipo de cultivo, vocação, etc.). Os índios Uapixana identificam e classificam oito tipos básicos de solos, que ocorrem individualmente ou formando associações: Imii Wyzda'u (Terra Amarelada), Imii Wyza'u (Terra Vermelha), Imii Pudiidiu (Terra Preta), Imii Pudiidiza'u (Terra Roxa), Katy Bara Pudiidiu (Barro Arenoso), Imii Kaxidia'u (Estopa Preta), Imii Katy Bara Pudiidiu Naik Baraka'u (Terra Arenosa Preta e Branca) e Imii Wyzadaza'u Rik Pudiidiu (Miscelânea de Terra Amarela, Roxa e afloramentos de rocha), abordando características morfológicas, físicas e químicas e as principais limitações quanto ao uso agrícola. Há relação evidente entre a dimensão do saber etnopedológico o saber etnoecológico, em sentido amplo. A experiência etnopedológica representa, assim, a extensão de uma abrangente cadeia de inter-relações homem-meio, dentro
\end{abstract}

\footnotetext{
(1) Trabalho recebido para publicação em abril de 2006 e aprovado em janeiro de 2007.

(2) Professor do Departamento de Solos e Irrigação, Universidade Federal de Roraima - UFRR. Campus Cavamé, BR 174, Km 12, CEP 69300-000 Boa Vista (RR). E-mail: vale.junior@click21.com.br

(3) Professor do Departamento de Solos, Universidade Federal de Viçosa - UFV. CEP 36570-000 Viçosa (MG). E-mail: carlos.schaefer@ufv.br

(4) Professor do Instituto de Geociências - IGEO/UFRR. Campus Paricarana, Av. Ene Garcez 2413, CEP 69304-000 Boa Vista (RR). E-mail: javcosta@dgl.ufrr.br
} 
do princípio universal da ecologia humana da paisagem. O diálogo etnopedológico travado entre a comunidade indígena e os pedólogos trouxe contribuições muito relevantes e mutuamente benéficas: facilitou a transferência de conhecimento entre dois saberes, in loco, desvendando boa parte das relações etnopedológicas e etnoecológicas e refletindo sobre "como" e "por que" cada grupo identificava um dado tipo de solo. Permitiu ainda delinear o esboço da distribuição dos solos com base no saber indígena, utilizando a extrapolação cartográfica disponível ao pedólogo; esse fato facilitou o próprio mapeamento convencional, especialmente no reconhecimento de inclusões e associações de solos. De forma mais destacada, a experiência permitiu ainda uma real comunicação e aproximação entre os agentes do saber (indígenas e técnico), com base na troca e em descobertas mútuas de conhecimentos, gerando uma sinergia que aproxima o técnico e o indígena, com resultados práticos palpáveis, que extrapolam o próprio objetivo inicial do levantamento de solos da TI Malacacheta.

Termos de indexação: Amazônia, solos indígenas, terra preta de índio, etnoecologia, Índios Uapixana, índios Macuxi.

\title{
SUMMARY: ETHNOPEDOLOGYAND KNOWLEDGE TRANSFER:DIALOGUE BETWEEN INDIANS AND SOIL SCIENTISTS IN THE MALACACHETA INDIAN TERRITORY, RORAIMA, AMAZON
}

\begin{abstract}
Ethnopedology deals mainly with indigenous knowledge on pedo-diversity. In this sense, the agricultural and cultural traditions of the Wapishana Indians in Roraima, of the Arawak linguistic background, constitute a relevant pool of ethno-scientific knowledge in Amazonia. The Federal University of Roraima has increasingly acknowledged their importance in the Indigenous Education undergraduate courses. In this study, the ethnopedological classifications of the Wapishana Indians were confronted with the Brazilian System of Soil Classification in a soil survey of the Malacacheta Indian Territory. The ethnopedological classification of Wapishana Indians identifies and separates all environmental segments of the area, relating easily recognizable aspects of the soilscape (color, texture, depth, vegetation) with observable aspects (land use, cultivation type, suitability). The Wapishana classify eight basic soil types, that occur either separately or in associations: Imii Wyzda'u (Yellowish earth), Imii Wyza'u (Red earth), Imii Pudiidiu (Black Earth), Imii Pudiidiza'u (Dusky-Red Earth), Katy Bara Pudiidiu (Sandy loam), Imii Kaxidia'u (Black spongy), Imii Katy Bara Pudiidiu Naik Baraka'u (Black and White Sandy Ground) and Imii Wyzadaza'u Rik Pudiidiu (Mixed Yellowish earth, Dusky-Red earth and Rock outcrops), based on morphological, physical and chemical attributes, as well as land use limitations. There are clear relationships between the ethnopedological knowledge and the ethno-ecological dimension of the Wapishana culture, in the broadest sense. The ethnopedological observations, thus, represent an expression of the interwoven network of man-environment relationships, seen in a framework of universal principles of human/ landscape ecology. The intense ethnopedological dialogue between soil scientists and Indians resulted in enriching, mutually beneficial contributions: the proper knowledge transfer in loco between two different traditions, the clarification of great part of the ethnopedological perceptions of both groups, and the understanding on how and why each group identified a given soil. Moreover, a soil map based on indigenous knowledge was drawn up, in an extrapolation of the cartographical base available to pedologists; this supported the conventional soil mapping of the area as well, especially in the recognition of soil inclusions and associations. Particularly, the experience allowed effective communication and approach of the representatives of indigenous and technical knowledge, based on knowledge transfer and mutual discoveries of understanding, creating synergy effects with promising results, which outreached the original aim of soil mapping of the Malacacheta Indian Territory.
\end{abstract}

Index terms: Amazon, indigenous soils, Indian black earth, ethnoecology, Wapishana Indians, Macuxi Indians. 


\section{INTRODUÇÃO}

O corpo de conhecimento indígena e local sobre a diversidade de solos e usos é o foco principal da etnopedologia, termo introduzido por Williams \& Ortiz-Solorio (1981) e amplamente aplicado aos estudos etnológicos por Posey, no alto Xingu (Posey, 1986; Hecht \& Posey, 1989). O interesse despertado pela abordagem "etnopedológica" no seio da comunidade de pedólogos no Brasil é bem evidenciado pela recente revisão abrangente de Alves \& Marques (2005) sobre o tema, em que destacam a antiguidade e validade dos diversos enfoques etnocientíficos, evoluídos ao longo da história.

Foi a partir de saberes populares, traduzidos na longa e sólida experiência histórica dos povos eslavos no cultivo do solo, que nasceu a pedologia moderna, com V. Dokuchaev, na última quadra do século XIX. A etimologia russa de nomes como Chernozem, Solods e Solonetz tem, assim, evidente origem etnopedológica, apesar de sua incorporação de há muito nos sistemas gerais de classificação dos solos, em diversos países.

Ao descrever o meio físico em Roraima e as relações com a ecologia humana indígena, Schaefer \& Eden (1995) destacaram a estreita identificação dos diferentes povos indígenas com certos domínios ambientais do Estado, ilustrando a co-evolução dos povos indígenas, suas culturas e seus "saberes", com o meio físico e biótico em que se desenvolveram ao longo da história. Esse fato foi abordado, em escala mais regional, com respeito aos povos indígenas Macuxis e Ingarikós na área indígena Raposa Serra do Sol, recém-demarcada (Schaefer et al., 2005), evidenciando os padrões diferenciados de ecologia humana em cada grupo particular. Por outro lado, Roraima é o Estado da Amazônia com a mais ampla diversidade étnica e de ecossistemas, em razão das enormes variações climáticas e pedológicas, e pulsos de ocupação humana (Schaefer \& Dalrymple, 1995; Schaefer, 1997).

Um dos maiores problemas relativos ao manejo dos solos refere-se à dificuldade na identificação destes onde não existem levantamentos disponíveis. Um bom mapeamento de solos facilita a determinação da sua vocação agrícola, com reflexo direto na conservação de solo e água e na preservação ambiental, em sentido amplo. Assim, a classificação dos solos e o conhecimento de seus atributos são fundamentais para o seu correto manejo; serve para organizar o conhecimento sobre eles, sendo necessário que suas características físicas e químicas sejam conhecidas, a fim de compará-los e classificá-los. Dependendo dos objetivos, os solos podem ser enquadrados em uma classificação taxonômica, cuja estrutura obedece a uma hierarquia baseada em características e propriedades (morfológicas, físicas e químicas), ou em classificação técnica ou interpretativa, cuja finalidade é organizar os solos conforme suas limitações perante um dado uso qualquer, não apenas agrícola.
Em Roraima, a Universidade Federal buscou, de forma pioneira, a inclusão das diferentes culturas indígenas por meio do Núcleo Insikiran de Educação Indígena, que visa resgatar a memória cultural dos povos deste Estado. O presente trabalho é uma contribuição ao resgate cultural dos índios Uapixana, entre os mais antigos povos Aruaques que ocuparam o atual Estado de Roraima.

Este trabalho objetivou identificar e classificar os solos nos diversos ambientes da terra indígena Malacacheta, identificando suas características e propriedades mais relevantes, bem como suas vocações para o uso agrícola, por meio de um processo de diálogo etnopedológico entre pedólogos e agricultores indígenas, caracterizando o "saber" etnopedológico local e suas interações com o saber científico.

\section{MATERIAL E MÉTODOS}

\section{Área de estudo e características fisiográficas}

O território indígena Malacacheta encontra-se na parte central do Estado de Roraima, cuja sede está localizada nas coordenadas geográficas de $02^{\circ} 40^{\prime} 11^{\prime \prime} \mathrm{N}$ e $60^{\circ} 27^{\prime} 21^{\prime \prime} \mathrm{W}$ e soma, em conjunto com as comunidades Uapixana vizinhas de Canauani, Laje, Campinarana e Tabalascada, um total de 52,8 mil hectares. Constitui zona de transição (ecótono) entre o cerrado, as campinas e as florestas, caracterizando área de elevada biodiversidade (Figura 1). A agricultura praticada é de subsistência, com uso de fogo para preparo da terra, e pousios variáveis de acordo com as características dos solos. De maneira geral, a área é dominada por solos de fertilidade natural muito baixa (Quadro 1).

A área de estudo compreende duas porções distintas, sendo representado, em menor proporção, o extenso domínio savânico norte-amazônico (cerrados do Rio Branco), sobre o qual se encontra assentado o principal núcleo habitacional da sede da maloca Malacacheta. A segunda porção, mais extensa, está representada pela região de Floresta Tropical Úmida.

O Pediplano Rio Branco compreende uma área extensamente plana, correspondendo a segunda fase do ciclo Pliopleistoceno, com vasta distribuição espacial em todo o norte amazônico. A planura é algumas vezes interrompida por pequenas ondulações e depressões incipientes, por onde meandram igarapés, intermitentes ou não, marcados por um alinhamento de veredas de buritis e inúmeras lagoas fechadas ou parcialmente drenadas por igarapés (Schaefer, 1991). A precipitação gira em torno de 1.350 a $1.920 \mathrm{~mm}$, com período seco bem definido (Schaefer, 1997; Agostinho, 2005).

O domínio de cerrados é predominantemente representado por Latossolos Amarelos e Latossolos Vermelho-Amarelos, associados a Argissolos Amarelos, cujo material de origem são sedimentos argilo-arenosos 
da Formação Boa Vista (Terciário / Quaternário), com ocorrência de alguns inselbergs, que representam, localmente, relevos serranos (Serra da Malacacheta, Serra da Lua).

São solos profundos, com sequência de horizontes A, B e C com horizonte A moderado e B Latossólico ou B textural, muito intemperizados, ácidos a fortemente ácidos, com saturação de $\mathrm{Al}$ elevada, de baixa fertilidade natural (Quadro 1), havendo demanda muito alta de fertilizantes e corretivos (Vale Jr., 1999). A coloração é amarelada (bruno-amarelada a bruno forte) de matizes 10YR a 5YR, e a fração argila tem natureza essencialmente caulinítica. Apresentam-se coesos (duro a muito duro quando seco), principalmente nos horizontes de transição $\mathrm{AB}$ ou BA ou mesmo no topo do C (Embrapa, 1983; BRASIL, 1975; Schaefer, 1991, 1997). Em meio a esses solos ocorrem manchas de Gleissolos e Neossolos Quartzarênicos, igualmente de baixa fertilidade natural.

O cerrado (savana) é representado por núcleos do tipo campo sujo/campo cerrado, cuja transição com a floresta tropical ocorre de forma abrupta. A principal característica do cerrado, regionalmente chamado Lavrado, é a forma campestre aberta, com poucos elementos arbóreos ou arbustivos, marcado por depressões suaves, por onde se alinham extensas veredas de buritis. Ocorrem também matas ciliares ao longo das principais drenagens. Segundo San Jose \& Medina (1985), a origem das savanas amazônicas se deve a fatores como precipitação sazonal, solos, geomorfologia, fogo e atuação do homem. No caso das savanas roraimenses, o domínio dos solos coesos, o período seco prolongado e o fogo são os principais fatores responsáveis por essa formação fitogeográfica.

\section{A Terra Indígena Malacacheta}

A área está localizada na porção sudeste do Estado de Roraima, distando aproximadamente $35 \mathrm{~km}$ a leste da capital Boa Vista (Figura 1).
A terra indígena Malacacheta possui ocupação tradicional predominante Uapixana (Wapishana), mas com cerca de dez por cento de índios Makuxis, que passaram a viver na comunidade após casamentos interétnicos. Segundo os registros históricos, os Uapixana ocupam a região do entorno da Serra da Lua há pelo menos três séculos.

\section{Métodos de Levantamento}

O trabalho de escritório constou de pesquisas bibliográficas, confecção de blocos-diagrama, tabelas, elaboração dos mapas temáticos, organização e interpretação dos dados analíticos e classificação dos solos segundo o Sistema Brasileiro de Classificação de Solos (Embrapa, 1999) e os critérios etnopedológicos.

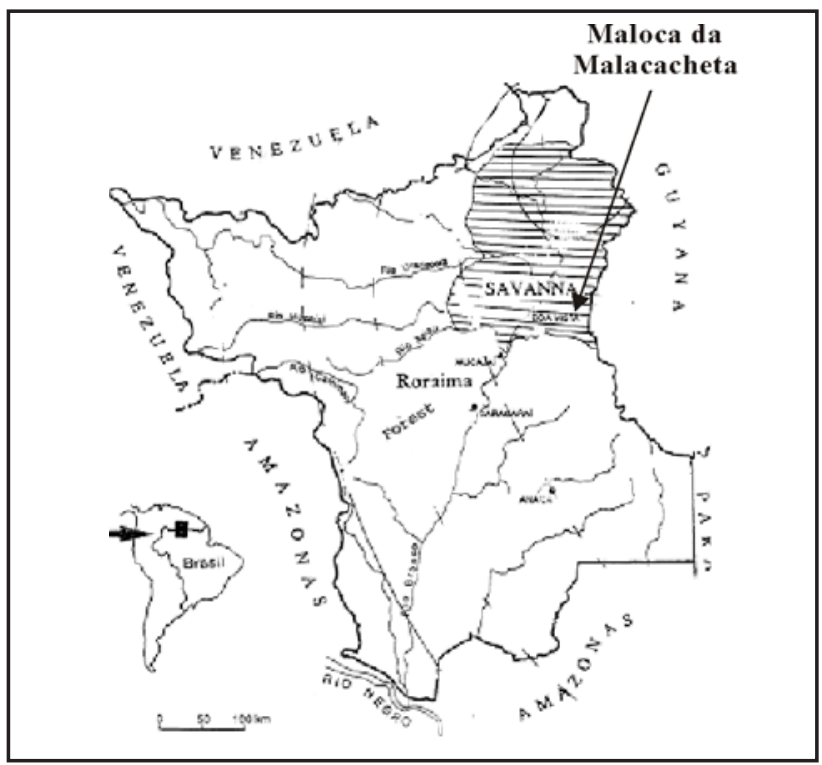

Figura 1. Localização do TI Malacacheta, no sudeste de Roraima.

Quadro 1. Características das principais classes de solos encontradas na área de estudo

\begin{tabular}{|c|c|c|c|c|c|c|}
\hline & \multicolumn{2}{|c|}{ Latossolo Amarelo ${ }^{(1)}$} & \multicolumn{2}{|c|}{ Neossolo Quartzênico ${ }^{(2)}$} & \multicolumn{2}{|c|}{ Latossolo Vermelho-Amarelo ${ }^{(2)}$} \\
\hline & A & Bw & A & $\mathbf{C}$ & A & Bw \\
\hline $\mathrm{pH}\left(\mathrm{H}_{2} \mathrm{O}\right)$ & 4,8 & 5,2 & 5,1 & 5,2 & 5,1 & 5,4 \\
\hline $\mathrm{Ca}^{2+}$ & 0,21 & 0,08 & 0,2 & 0,15 & 0,60 & 0,45 \\
\hline $\mathrm{Mg}^{2+}$ & 0,09 & 0,02 & 0,15 & 0,10 & 0,23 & 0,10 \\
\hline $\mathrm{K}^{+}$ & 0,04 & 0,03 & 0,03 & 0,02 & 0,04 & 0,02 \\
\hline $\mathrm{Al}^{3+}$ & 0,547 & 0,287 & 0,55 & 0,6 & 0,45 & 0,25 \\
\hline $\mathrm{H}^{+}$ & 1,445 & 0,897 & 1 & 0,55 & 2,05 & 1,20 \\
\hline CTC total & 2,438 & 1,390 & 1,95 & 1,4 & 3,40 & 1,95 \\
\hline Saturação por bases & 18,37 & 14,8 & 22,5 & 19,00 & 25,5 & 24,7 \\
\hline $\mathrm{CO}\left(\mathrm{g} \mathrm{kg}^{-1}\right)$ & 0,65 & 0,23 & 0,28 & 0,12 & 0,59 & 0,123 \\
\hline $\mathrm{N}$ total & 0,03 & 0,02 & 0,05 & 0,04 & 0,07 & 0,035 \\
\hline
\end{tabular}

(1) Média de 12 perfis. ${ }^{(2)}$ Média de 6 perfis.

Fonte: Embrapa (1983); BRASIL (1975); Schaefer (1997); Vale Jr. (1999). 
Por meio de cartas e imagens na escala 1:100.000, foi demarcada a área de estudo e selecionados os pontos de observações de campo. Em seguida, foram delimitadas as unidades de mapeamento, sendo elaborada uma legenda preliminar de solos a ser checada em campo, por meio do caminhamento livre. Procurou-se também relacionar a vegetação, o relevo e o uso com o tipo de solo.

Após os trabalhos de campo, realizou-se um novo reajuste para o traçado final entre as unidades de mapeamento, considerando-se os resultados das análises de laboratório e as descrições morfológicas dos perfis e tradagens realizadas no campo. Os dados analíticos e o mapa pedológico convencional não constam dos resultados apresentados neste artigo.

Quanto à classificação dos solos, adotou-se o Sistema Brasileiro de Classificação de Solos (Embrapa, 1999), fazendo-se também uma correlação com a classificação étnica. Consideraram-se as propriedades diagnósticas, os horizontes diagnósticos e os demais critérios para definição das classes de solos. Em face da escala mais detalhada das bases cartográficas (1:100.000) e do nível do estudo (reconhecimento), a legenda definitiva das unidades de solos foi formada por associações de solos, pois o nível de estudo não permite a individualização em unidades mais homogêneas.

Foi adotada uma metodologia que permitiu a intensa participação da comunidade indígena, por meio de oficinas de trabalho, quando foram aplicados questionários e trocadas informações sobre os solos. Durante as oficinas, houve oportunidade de verificar como os agricultores indígenas relacionam a fertilidade do solo com atributos como cor e vegetação, e como determinadas espécies vegetais indicam solos de melhor qualidade. Os tipos de uso e manejo das terras adotados pelos indígenas foram também inventariados e discutidos, com base nas características apontadas pelos índios.

Com base nas informações colhidas nas oficinas, $\mathrm{e}$ por meio de trabalho de campo, com caminhamento livre por toda a área indígena, elaborou-se o esboço preliminar da classificação etnopedológica Uapixana dos solos da TI Malacacheta, em que as características de cor e textura dos solos são utilizadas como diagnósticas pelos índios, estando intimamente relacionadas com o uso e a aptidão agrícola das terras, considerando as necessidades locais da agricultura indígena. Paralelamente, foi feito o reconhecimento de solos da TI Malacacheta, evidenciando as relações com o saber etnopedológico local.

$\mathrm{Na}$ delimitação das unidades de mapeamento foi utilizada a base cartográfica disponível, em escala de 1:100.000, com auxílio direto dos índios, separando as unidades pelas principais feições topográficas e hidrográficas existentes. O levantamento de solos da TI Malacacheta baseou-se na experiência prévia dos autores na área e em dados de levantamentos da Embrapa (BRASIL, 1975; Embrapa, 1983; Schaefer, 1997). A descrição e a coleta dos perfis, não incluídas neste trabalho, seguiram as normas preconizadas por Lemos \& Santos (1984), e as análises foram realizadas de acordo com Embrapa (1997).

\section{RESULTADOS E DISCUSSÃO}

A partir das oficinas e do reconhecimento de campo junto aos índios, foram identificados e classificados oito tipos básicos de solos, que ocorrem individualmente ou formando associações: Imii Wyzda'u (Terra Amarelada), Imii Wyza'u (Terra Vermelha), Imii Pudiidiu (Terra Preta), Imii Pudiidiza'u (Terra Roxa), Katy Bara Pudiidiu (Barro Arenoso), Imii Kaxidia'u (Estopa Preta), Imii Katy Bara Pudiidiu Naik Baraka'u (Terra Arenosa Preta e Branca) e Imii Wyzadaza'u Rik Pudiidiu (Associação de Terra Amarela, Roxa e afloramentos de rocha). Na figura 2 podem ser observadas as relações geomorfopedológicas da área da Terra Indígena Malacacheta. A seguir são descritas as oito classes de solos indígenas, considerando suas principais características morfológicas, limitações e uso atual. O mapa correspondente ao levantamento etnopedológico da TI Malacacheta é ilustrado na figura 3.

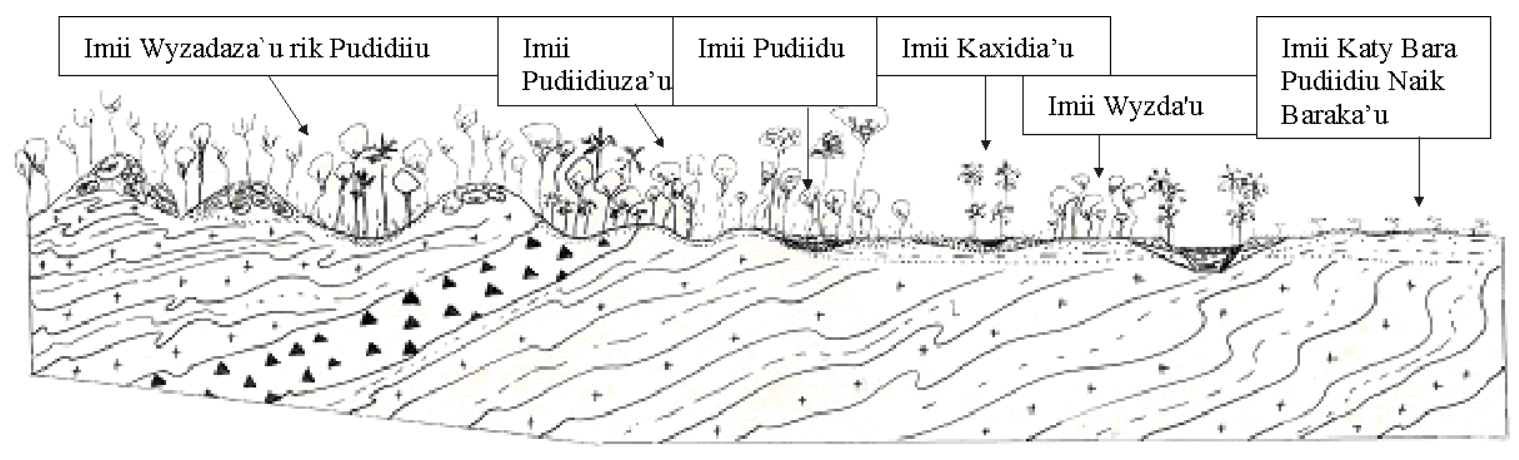

Figura 2. Diagrama esquemático de alguns dos solos presentes na TI Malacacheta, reconhecidos pelos índios Uapixana. 


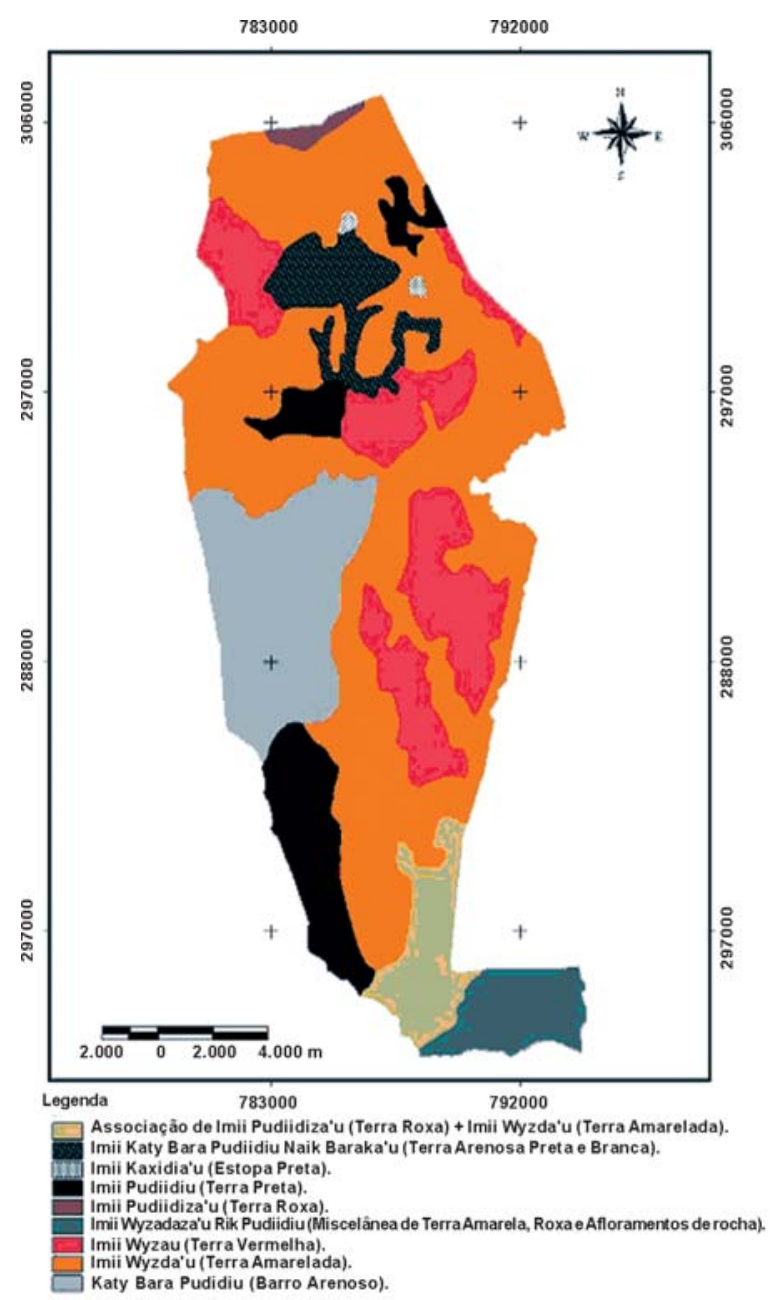

Figura 3. Mapa etnopedológico Uapixana da TI Malacacheta, Roraima, Amazônia.

As classes de solos (ou terras) descritas pelos Uapixanas abordaram características morfológicas, físicas e químicas e as principais limitações quanto ao uso agrícola. Por se tratar de classificação etnopedológica, em que a cor e a textura são as principais características diagnósticas usadas como critérios de fertilidade e manejo das terras, ela não representa uma chave de identificação e classificação de solos de forma hierárquica, à semelhança do descrito por Cooper et al. (1995) para os índios Xicrin.

No quadro 2 são apresentadas as principais relações observadas entre os tipos (classes) de solos indígenas (do mapa etnopedológico) e as classes de solos da legenda pedológica utilizada no mapa de reconhecimento dos solos da Maloca. Há boa correlação entre a maioria das classes do levantamento pedológico de reconhecimento efetuado e o levantamento etnopedógico Uapixana.

\section{Imii Wyzda'u (Terra Amarelada)}

Esta é a classe de solos mais comum na área da Maloca da Malacacheta. São solos profundos, bem drenados, com características bastante uniformes ao longo do perfil e cor amarelada. A estrutura é granular bem definida e desenvolvida. Estão posicionados em áreas planas ou suave-onduladas, com boa infiltração de água, mas com presença de uma camada coesa (dura) próxima de $30 \mathrm{~cm}$ de profundidade, que torna os solos duros quando secos, ocasionando erosão laminar no início do período chuvoso, quando a água infiltra mais lentamente. Ocorrem ainda em associação com a classe de Imii Pudiidiza'u (Terra Roxa) na parte mais ao sul da Maloca. Correspondem aos Latossolos Amarelos do Sistema Brasileiro.

Apresentam textura argilosa e média, com teores de argila acima de $30 \%$. Segundo os Uapixanas, são solos de baixa fertilidade natural. A vegetação natural é de Mata Baixa transição para Cerrado, com espécies como farinha-seca, luvireira e árvores de casca grossa. Nessas terras são plantadas culturas como mandioca e banana, com menor presença de feijão, laranja, coco, limão, tangerina, ingá, manga, caju, milho e batatadoce, sendo os pousios requeridos muito longos. Mostram-se intensamente degradados física e quimicamente com o fogo, após cultivos sucessivos, corroborando os dados de San José \& Medina (1975) para solos amarelos do norte da Amazônia e Eden et al. (1991) em solos semelhantes aos descritos na Maloca, no Lavrado de Roraima.

\section{Imii Wyza'u (Terra Vermelha)}

São solos profundos, bem drenados, com características bastante uniformes ao longo do perfil, apresentando cor vermelha característica. A estrutura é bem desenvolvida, do tipo granular. Estão posicionados em áreas planas a onduladas, com boa infiltração de água, próximas ao Igarapé da Serra (Midikyu Wa'u), e em áreas virgens ao sul. Correspondem em boa parte aos Latossolos VermelhoAmarelos e Vermelhos, do Sistema Brasileiro de Classificação de Solos.

Apresentam textura argilosa, com teores de argila sempre acima de $35 \%$; segundo os Uapixanas, são áreas de fertilidade natural mediana, cuja vegetação natural de Mata Estacional possui porte mais alto, com pau-rainha, palmeira-inajá, freijó e cumaru. As principais culturas são mandioca, banana, feijão, laranja, milho e batata-doce. Os pousios são longos, mas geralmente menores que para os solos Imii Wyzda'u, anteriormente descritos.

\section{Imii Pudiidiu (Terra Preta)}

São solos profundos, bem drenados, apresentando cor escura na superfície e avermelhada/amarelada em subsuperficie. Possuem estrutura granular bem desenvolvida. Estão posicionadoas em áreas de encostas baixas de serra e morros, com boa infiltração de água, próximas ao igarapé do Cavalo (Kawaru Wa'u).

São mais arenosos em superfície e argilosos em subsuperfície, com teores de argila acima de $30 \%$. São terras relativamente mais férteis, sendo 
Quadro 2. Correlação entre solos e unidades de mapeamento de acordo com o Sistema Brasileiro de Classificação de Solos (Embrapa, 1999) e a Classificação Etnopedológica Uapixana dos solos da Maloca da Malacacheta

Unidades de Mapeamento do Levantamento Pedológico da TI Malacacheta (conforme Embrapa, 1999)

\section{Correlação com classificação etnopedológica Uapixana}

LAd1 - Latossolo Amarelo distrófico típico+ Argissolo Amarelo distrófico latossólico, ambos A moderado textura média/argilosa relevo plano, vegetação campo Cerrado e Floresta Tropical Úmida.

LAd1 - Latossolo Amarelo distrófico típico+ Neossolo Quartzarênico hidromórfico, ambos A moderado relevo plano, vegetação campo Cerrado e Floresta Tropical Úmida.

LVAd1 - Latossolo Vermelho-Amarelo distrófico típico+ LVd Latossolo Vermelho distrófico, ambos A moderado textura argilosa, vegetação campo Cerrado e Floresta Tropical Úmida.

LVAd2 - Latossolo Vermelho-Amarelo distrófico típico+ Argissolo Vermelho-Amarelo distrófico latossólico, ambos A moderado textura argilosa relevo plano, vegetação Floresta Tropical Úmida.

GMd - Gleissolo Melânico distrófico + Argissolo Acinzentado distrófico + Neossolo Flúvico Tb distrófico, ambos relevo plano, vegetação campo higrófilo ou mata ciliar.

RQg - Neossolo Quartzarênico hidromórfico A moderado relevo plano, vegetação Campo Cerrado e mata + Espodossolo Humilúvico

hiperespesso típico relevo plano vegetação de Campinarana Arbórea.

RLd - Neossolo Litólico distrófico + Cambissolo Háplico Tb distrófico A moderado relevo ondulado a montanhoso vegetação Floresta Tropical Úmida.
Imii Wzyda'u (Terra Amarelada)

Katy Bara Pudiidiu (Barro Arenoso, em inclusões)

Imii Wzyda'u (Terra Amarelada)

+ Katy Bara Pudiidiu (Barro Arenoso)

Imii Wyzau (Terra Vermelha)

Imii Pudiidizau(1) (Terra Roxa, em inclusões)

Imii Wyzau (Terra Vermelha)

Imii Pudiidiu (Terra Preta, como inclusão)

Imii Kaxidia'u (Estopa Preta)

Katy Bara Pudiidiu (Barro Arenoso)

Imii Katy Bara Pudiidiu Naik Baraka'u

(associação de Terra Arenosa Preta e

Branca)

Imii Wyzadazau Rik Pudiidiu (associação de Terras Amarela, Roxa e afloramento de rocha).

(1) As Terras Roxas da área mapeada correspondem de forma geral ao Nitossolo Vermelho distrófico latossólico (NVd), correlatas às Terras Roxas descritas por Vale Jr. (1999).

intensamente utilizadas, suportando cultivos por mais de quatro anos consecutivos, mas requerendo pousios longos. A vegetação natural é pau-rainha, freijó, cumaru, jatobá e pau-louro. Nestes solos são plantadas culturas como mandioca, banana, feijão, milho, mamão e abóbora, com intensidade maior de cultivo que nos dois solos anteriores. São identificados como Terra Preta de origem antrópica (indígena), sendo aparentemente correlatos às chamadas Terras Mulatas da Amazônia, sendo menos ricas que as Terras Pretas verdadeiras do Solimões/Amazonas (Schaefer et al., 2000). Correspondem, em boa parte, a Latossolos Amarelos antropogênicos.

\section{Katy Bara Pudiidiu (Barro Arenoso)}

Compreende uma classe de solos de textura média, onde a concentração maior de areia favorece a boa infiltração de água. São solos profundos, de cor amarelada clara a acinzentada em subsuperfície, sendo mais escuros na superfície; estão situados em áreas planas, próximas ao igarapé do Genipapo (Saunuru Wa'u), com fertilidade natural baixa a mediana, embora ácidos.
As características supramencionadas são favoráveis ao uso dessas terras com diversas culturas anuais e fruteiras. Atualmente são terras utilizadas com melancia, laranja, coco, cacau, feijão e milho. Esgotam-se rapidamente com o cultivo e a queima, segundo os Uapixana. Correspondem, em boa parte, a Argissolos Acinzentados e Argissolos Amarelos, do Sistema Brasileiro.

\section{Imii Kaxidia'u (Estopa Preta)}

São solos hidromórficos, que apresentam alta concentração de matéria orgânica, formados em ambientes mais baixos e alagados, ao longo de igarapés e lagoas, onde as condições de alagamento, em determinado período do ano, favorecem o acúmulo de matéria orgânica parcialmente decomposta. A maior mancha separada pelos índios situa-se próxima ao igarapé do Jaboti (Wyrad Wa'u).

Devido à alta concentração de matéria orgânica, os solos mostram cor escura (preta) na superfície e acinzentada e clara em profundidade; a textura varia desde arenosa até argilosa (barro). 
A elevada concentração de matéria orgânica, apesar da acidez, confere certa fertilidade a essas terras, podendo ser cultivadas com diversas culturas anuais, exceto em período de alagamento. Atualmente são cultivadas com feijão.

Não chegam a formar turfeiras típicas. Correspondem, em grande parte, a Gleissolos Melânicos, do Sistema Brasileiro de Classificação de Solos.

\section{Imii Katy Bara Pudiidiu Naik Baraka'u (Terra Arenosa Preta e Branca)}

Compreende solos constituídos por material mineral arenoso, com areias grossas e finas e teor de argila sempre abaixo de $15 \%$. Ocorrem em relevo plano, ao longo de igarapés, como o igarapé do Lauriano (Lauriano Wa'u) e igarapé do Jaboti (Wyrad Wa'u), sob vegetação de Cerrado ou Campina Amazônica.

São profundos, com cores esbranquiçadas e pretas em superfície, que indicam ambiente onde ocorre elevação e rebaixamento sazonal do nível de água. Podem ou não apresentar horizonte escuro subsuperficial (horizonte espódico), não sendo este um critério observado pelos índios Uapixana em sua identificação.

Em decorrência da constituição essencialmente arenosa, são solos muito pobres em nutrientes, ácidos, e não possuem reserva nutricional que possa ser liberada gradativamente. Apresentam ainda sérias limitações devido ao lençol freático elevado, limitando o uso agrícola. Não são normalmente cultivados pelos indígenas. Correspondem a uma associação de Espodossolos e Neossolos Quartzarênicos.

\section{Imii Pudiidiza'u (Terra Roxa)}

São solos profundos, bem drenados, com características bastante uniformes ao longo do perfil, apresentando cor vermelha, com estrutura em blocos, de grau forte. Estão posicionados em áreas suaveonduladas até onduladas, com boa infiltração de água. São muito semelhantes às terras vermelhas, mas apresentam maior fertilidade natural, com maior concentração de nutrientes para as plantas.

Apresentam textura argilosa, com teores de argila acima de $35 \%$. São solos de boa qualidade, cuja vegetação natural é pau-rainha, palmeira-inajá, freijó, e cumaru. Nessas terras são plantadas culturas como mandioca, banana, caju, tangerina, feijão, laranja, milho e batata, com bom rendimento e pousios mais curtos que nos demais solos. Correspondem a Nitossolos Vermelhos distróficos, em sua maioria.

Imii Wyzadaza'u Rik Pudiidiu (Associação de Terra Amarelada, Roxa, com afloramentos de rochas)

Essa classe é reconhecida pelos indígenas como uma associação de solos amarelados e roxos, em relevo montanhoso, na Serra da Lua (Kayzyb), onde estão presentes também solos rasos, cascalhentos ou pedregosos na superfície.

Essas terras apresentam as mesmas características descritas anteriormente nas classes de terras amareladas e vermelhas, merecendo destaque a fertilidade natural, pois, em virtude da rocha do local, essas terras são mais ricas em nutrientes. São terras utilizadas atualmente com amendoim, taioba, pimentão, cana, melão, feijão e batata-doce.

Associados a estes solos estão os Neossolos Litólicos (solos rasos) ou tipos de terrenos muito rasos, com profundidades de até $25 \mathrm{~cm}$, cascalhentos, dominados por afloramentos de rocha. Por serem muito rasos, possuem limitação muito séria ao cultivo, pela pequena espessura, pois o substrato granítico/ gnaíssico, sendo pouco fraturado, dificulta ou impede a penetração do sistema radicular das plantas. A presença freqüente de cascalhos, a pedregosidade e rochosidade, a pequena espessura e o relevo acidentado são fatores que restringem sua utilização agrícola, sendo mais indicados para preservação da fauna e flora, como já é a destinação natural da unidade pelos indígenas. São áreas de concentração e refúgio de caça. Correspondem a uma associação de Neossolos Litólicos e Cambissolos Háplicos, ambos distróficos, no Sistema Brasileiro de Classificação de Solos.

Com base nas oficinas realizadas, foi possível verificar que há uma aproximação evidente entre a dimensão do saber etnopedológico com o saber etnoecológico, em sentido amplo, sendo estes indistinguíveis, corroborando relatos de pioneiros como Conklin (1954) e Moran (1990) em estudos com outros povos primitivos. A percepção etnopedológica representa, assim, a extensão de uma ampla e abrangente cadeia de inter-relações dinâmica homemmeio, denotando o princípio universal da ecologia humana da paisagem.

Talvez mais importante que os aspectos supramencionados, o diálogo permitiu ainda uma comunicação real e efetiva aproximação entre os agentes do saber indígena e técnico-científico, baseada na troca e em descobertas mútuas de conhecimentos, gerando uma sinergia que aproxima o técnico e o indígena (popular), com resultados práticos palpáveis, que extrapolam o próprio objetivo inicial do levantamento de solos da Maloca.

\section{CONCLUSÕES}

1. O sistema de classificação etnopedológica da comunidade indígena da Malacacheta consegue identificar e separar de forma objetiva todos os compartimentos ambientais de ocorrência na área, cumprindo o objetivo primordial de relacionar aspectos de simples percepção e identificação (cor, textura, profundidade, vegetação) com aspectos práticos, cognoscíveis (uso, tipo de cultivo, vocação agrícola, etc.). 
2. O diálogo etnopedológico travado entre a comunidade indígena e os pedólogos (entendidos aqui como agentes do saber científico) trouxe duas contribuições muito relevantes e mutuamente benéficas: (a) facilitou a transferência de conhecimento entre dois saberes, pela interação in loco e in vivo, permitindo verificar boa parte das relações etnopedológicas e etnoecológicas e apresentar e refletir sobre "como" e "por que" cada grupo identificava um dado tipo de solo, corroborando estudo de Agrawal (1995); e (b) permitiu delinear o esboço da distribuição dos solos com base no saber indígena, utilizando a extrapolação cartográfica disponível ao pedólogo; esse fato facilitou o próprio mapeamento convencional, especialmente no reconhecimento de inclusões e associações de solos.

\section{AGRADECIMENTOS}

Aos antropólogos e professores da Universidade Federal de Roraima Carlos Alberto Marinho Cirino e Erwin Frank, pela contribuição na fase campo, durante as oficinas de trabalho e a The Nature Conservancy do Brasil pelo financiamento do projeto.

\section{LITERATURA CITADA}

AGOSTINHO, J. A questão ambiental em Roraima. Ação Amb., $32: 7-11,2005$.

AGRAWAL, A. Indigenous and scientific knowledge. Indig. Develop. Monitor, 3:3-38, 1995.

ALVES, A.G.C. \& MARQUES, J.G.W. Etnopedologia: uma nova disciplina. In: VIDAL-TORRADO, P.; ALLEONI, L.R.F.; COOPER, M.; SILVA, A.P. \& CARDOSO, E.J., eds. Topicos em ciência de solo, 2005. V.4. p.321-344.

BARRERA-BASSOLS, N. \& ZINCK, J.A. Ethnopedology: A wordwide view on the soil knowledge of local people. In: WINKLER PRINS, A.M.G.A. \& SANDOR, J.A., eds. Ethnopedology. Geoderma, 111:171-195, 2003a.

BRASIL. Ministério das Minas e Energia. Projeto RADAMBRASIL. Folha NA. 20 Boa Vista e parte das Folhas NA. 21. Tumucumaque, Na. 20 Roraima e Na. 21. RJ, V.8, 1975.

CONKLIN, H.C. An ethnoecological approach to shifting agriculture. Trans. New York Acad. Sci., 17:133-142, 1954.

COOPER, M.; TERAMOTO, E.R.; VIDAL-TORRADO, P.; LEPSCH, I.F. \& GIANNINI, I.V. Classificação de solos utilizada pelos índios Xicrin do Cateté (Carajás, Pará). In: CONGRESSO BRASILEIRO DE CIÊNCIA DO SOLO., 25, Viçosa, 1995. Anais. Viçosa, MG, Sociedade Brasileira de Ciência do Solo, 1995. p.1497-1499.
EDEN, M.J.; FURLEY, P.A.; MCGREGOR, D.F.M.; MILLIKEN W. \& RATTER, J.A. Effect of forest clearance and burning on soil properties in northeastern Roraima, Brazil. For. Ecol. Manag., 38:283-290, 1991.

EMPRESA BRASILEIRA DE PESQUISA AGROPECUÁRIA EMBRAPA. Centro Nacional de Pesquisa de Solos. Manual de métodos de análise de solo. 2.ed. Rio de Janeiro, 1997. $212 \mathrm{p}$.

EMPRESA BRASILEIRA DE PESQUISA AGROPECUÁRIA EMBRAPA. Centro Nacional de pesquisa de solos. Sistema Brasileiro de Classsificação de Solos. Rio de Janeiro, 1999. $412 \mathrm{p}$.

EMPRESA BRASILEIRA DE PESQUISA AGROPECUÁRIA EMBRAPA. Serviço Nacional de Levantamento e Conservação de Solos. Levantamento de reconhecimento de média intensidade dos solos e avaliação da aptidão agrícola das terras da área do Pólo Roraima.Rio de Janeiro, 1983. (Boletim de Pesquisa, 18)

HECHT, S.B. \& POSEY, D.A. Preliminary results on soil management techniques on the Kayapo indians. Adv. Econ. Bot., 7:174-188, 1989.

LEMOS, R.C. \& SANTOS, R.D. Manual de descrição e coleta de solo no campo. 3.ed. Campinas, Sociedade Brasileira de Ciência do Solo, 1996. 83p.

MORAN, E.F. A ecologia humana das populações da Amazônia. Petrópolis, Vozes, 1990. 367p.

POSEY, D.A. Indigenous Knowledge and development: an ideological bridge to the future. Ci. Cult., 35:877-894, 1983.

SAN JOSE, J.J. \& MEDINA, E. Effects of fire on organic matter production and water balance in a tropical savanna. In: GOLLEY, F.B. \& MEDINA, E., eds. Tropical ecological systems. New York, Springer-Verlag, 1975. p.251-264.

SCHAEFER, C.E.G.R. \& DALRYMPLE, J. Landscape evolution in Roraima, North Amazonia, Planation, paleosols and paleoclimates. Zeit. Geomorph, 39:1-28, 1995.

SCHAEFER, C.E.G.R. Ecogeography and human scenario in Northeast Roraima, Brazil. Ci. Cult., 49:241-252, 1997.

SCHAEFER, C.E.G.R.; LIMA, H.N.; VALE JÚNIOR, J.F. \& MELLO, J.W.V. Uso dos solos e alterações da paisagem na Amazônia: cenários e reflexões. Bol. Museu. Paraense Emílio Goeld, Sér., Ci. Terra, 12:63-104, 2000.

SCHAEFER, C.E.G.R.; MOREIRA, G.F.; PORTES, R.C. \& MENDONÇA, B.A.F. Diagnóstico ambiental e sustentabilidade da área indígena Raposa-Serra do Sol. Ação Amb., 32:31-38, 2005.

SCHAEFER. C.E.G.R. \& EDEN, M. Os solos e os povos indígenas de Roraima: Um ensaio de ecologia humana. In: CONGRESSO BRASILEIRO DE CIÊNCIA DO SOLO, 25. Viçosa, 1995. Anais. Viçosa, MG, Sociedade Brasileira de Ciência do Solo, 1995. p.1494-1496. 
VALE JÚNIOR, J.F. Pedogênese e alterações dos solos sob manejo itinerante, em áreas de rochas vulcânicas ácidas e básicas, no Nordeste de Roraima. Viçosa, MG, Universidade Federal de Viçosa, 1999. 198p. (Tese de Doutorado)
WILLIAMS, B.J. \& ORTIZ SOLORIO, C.A. Middle American folk soil taxonomy. Ann.Assoc. Am. Geographers, 71:335$358,1981$. 